\title{
The modified Stroop paradigm as a measure of selective attention towards pain-related stimuli among chronic pain patients: a meta-analysis
}

Citation for published version (APA):

Roelofs, J., Peters, M. L., Zeegers, M. P. A., \& Vlaeyen, J. W. S. (2002). The modified Stroop paradigm as a measure of selective attention towards pain-related stimuli among chronic pain patients: a metaanalysis. European Journal of Pain, 6(4), 273-281. https://doi.org/10.1053/eujp.2002.0337

Document status and date:

Published: 01/01/2002

DOI:

10.1053/eujp.2002.0337

Document Version:

Publisher's PDF, also known as Version of record

Document license:

Taverne

Please check the document version of this publication:

- A submitted manuscript is the version of the article upon submission and before peer-review. There can be important differences between the submitted version and the official published version of record.

People interested in the research are advised to contact the author for the final version of the publication, or visit the DOI to the publisher's website.

- The final author version and the galley proof are versions of the publication after peer review.

- The final published version features the final layout of the paper including the volume, issue and page numbers.

Link to publication

\footnotetext{
General rights rights.

- You may freely distribute the URL identifying the publication in the public portal. please follow below link for the End User Agreement:

www.umlib.nl/taverne-license

Take down policy

If you believe that this document breaches copyright please contact us at:

repository@maastrichtuniversity.nl

providing details and we will investigate your claim.
}

Copyright and moral rights for the publications made accessible in the public portal are retained by the authors and/or other copyright owners and it is a condition of accessing publications that users recognise and abide by the legal requirements associated with these

- Users may download and print one copy of any publication from the public portal for the purpose of private study or research.

- You may not further distribute the material or use it for any profit-making activity or commercial gain

If the publication is distributed under the terms of Article 25fa of the Dutch Copyright Act, indicated by the "Taverne" license above, 


\title{
The modified Stroop paradigm as a measure of selective attention towards pain-related stimuli among chronic pain patients: a meta-analysis
}

\author{
Jeffrey Roelofs, ${ }^{a}$ Madelon L. Peters, ${ }^{a}$ Maurice P. A. Zeegers ${ }^{\mathrm{b}}$ and \\ Johan W. S. Vlaeyen ${ }^{a}$
}

Departments of ${ }^{a}$ Medical, Clinical and Experimental Psychology and ${ }^{b}$ Epidemiology,
Maastricht University, PO Box 616, 6200 MD Maastricht, The Netherlands

Although the modified Stroop paradigm is considered to be a prominent paradigm for investigating selective attention in emotional disorders, relatively few studies have applied this paradigm to examine selective attention in chronic pain patients. Moreover, the results from these studies are not robust. The purpose of this article is to review the evidence for attentional bias in chronic pain patients, by means of a meta-analysis. Data from five studies were pooled and summarized into a mean difference (MD). Significant MD estimations (in milliseconds) were found for both sensory pain words ( $\mathrm{MD}=26.7 ; 95 \%$ confidence interval $(\mathrm{CI}) 10.0-42.9$ ) and affective pain words ( $\mathrm{MD}=28.1 ; 95 \% \mathrm{CI} 0.4-55.8$ ). Meta-regression analysis indicated that methodological quality did not significantly affect the pooled MD estimation for both sensory pain words and affective pain words. Thus, the results from the present meta-analysis on studies applying the modified Stroop paradigm suggest that chronic pain patients selectively attend to both pain sensory and pain affective stimuli. Furthermore, the MD estimation did not depend on the methodological quality, tentatively indicating that even though studies differed in methodology, the results were rather consistent. Implications of the results are discussed. (C) 2002 European Federation of chapters of the International Association for the Study of Pain. Published by Elsevier Science Ltd. All rights reserved.

KeYwords: meta-analysis, Stroop, chronic pain, attentional bias, selective attention.

\section{INTRODUCTION}

During the past decade, researchers in experimental psychopathology have increasingly relied on cognitive psychology to account for emotional disorders, in particular depression and anxiety disorders. According to cognitive theory, people with these disorders process information differently compared to people without these disorders. This implies that an individual's affective status is

Paper received 26 July 2001 and accepted in revised form 3 December 2001.

Correspondence to: Jeffrey Roelofs, Department of

Medical, Clinical and Experimental Psychology,

Maastricht University, PO Box 616, 6200 MD Maastricht,

The Netherlands. Tel: +31-43-3881611;

Fax: +31-43-3884155; E-mail: J.Roelofs@dep.unimaas.nl associated with cognitive biases that favour the processing of information congruent with the affective state. Research in many syndromes, which has mainly been inspired by Beck's schema theory (Beck, 1976; Beck et al., 1986) and Bower's network theory (Bower, 1981, 1987), has identified biases in attention, memory and interpretation. Research into information processing has also been applied to chronic pain patients. There is good reason to assume that chronic pain patients exhibit a recall bias towards pain-related stimuli (Pincus et al., 1993, 1998; Pincus, 1998) and that interpretation bias takes place in pain patients (Pincus et al., 1994, 1996; Pincus, 1998). However, the possible existence of an attentional bias towards pain-related information remains unclear. In general, attentional bias can be 
defined as selective attention to (specific) concernrelated information. Attentional bias towards pain may serve the purpose of early detection of potentially dangerous pain-related stimuli.

One paradigm for investigating attentional bias has been the modified Stroop paradigm. Generally, in a modified Stroop paradigm categories of emotionally salient and neutral words are presented in different colours. Response times of patients to name the colour of each word are measured. Typically, colour naming is slowed down when words are threatening and relevant to the patients' concern, whereas no response delay is found with neutral words. Selective attention can be expressed in terms of interference, which is calculated by subtracting the colour naming time of neutral words from the colour naming time of concern-related words.

A relatively small number of studies regarding attentional bias applying a modified Stroop in chronic pain patients have been carried out. One of the first studies was performed by Pearce and Morley (1989). The results from this study indicated that pain patients displayed greater interference for pain-related sensory and affective words when compared with healthy controls. Thus, patients with chronic pain tended to show selective attention towards cues related to the expression of pain. However, depression was associated with a general delay in response times thereby contaminating the effect of pain on the observed attentional bias.

Boissevain (1994) further investigated the interaction between pain and depression by comparing performance on the Stroop task between four groups: depressed pain patients, non-depressed pain patients, pain-free depressed patients and pain- and depression-free controls. The results of this study support the presence of an attentional bias in pain patients: both pain groups were slower to name words from the sensory category than the neutral and positive categories.

Pincus et al. (1998) conducted two successive experiments to investigate the presence of attentional bias in chronic pain patients. The first study attempted to replicate the study of Pearce and Morley (1989). The second study described a more detailed examination of the effects of anxiety and depression in relation to attentional bias. Neither experiment provided evidence for an attentional bias towards pain stimuli in chronic pain patients when compared with a healthy control group. However, the interference score was influenced by measures of anxiety and depression rather than by pain itself.

A subsequent study using the modified Stroop paradigm found that patients with chronic pain but not healthy volunteers had delayed colour naming latencies for both sensory and affective words (Snider et al., 2000). In addition, delayed colour naming latencies for pain words were partly associated with high pain-specific cognitive anxiety (as measured with the Pain Anxiety Symptoms Scale (McCracken et al., 1992) and with lower levels of anxiety sensitivity (as measured with the Anxiety Sensitivity Index (Reiss et al., 1986).

The empirical evidence that chronic pain patients display attentional bias towards painrelated information is not robust. In addition, previous studies appear to have some theoretical and methodological inadequacies. Consequently, there is a need for a critical review of this area in the hope of summarizing and integrating the current literature. The purpose of the present study is to review systematically studies in chronic pain patients applying a modified Stroop paradigm, by means of a meta-analysis which provides a quantitative summary estimate (mean difference (MD)) of whether chronic pain patients selectively pay attention to pain-related information (i.e. display attentional bias). In the present meta-analysis, the impact of the methodological quality of the individual studies on the MD effect size is estimated. Finally, some concluding remarks and directions for future research are provided.

\section{MATERIALS AND METHODS}

\section{Search strategy and inclusion criteria}

Studies were identified through a computerized Pubmed (Medline), PsycInfo and Current Contents search up to July 2001. Furthermore, an intensive search on the worldwide web was 
performed in order to identify articles, abstracts or posters which may refer to the existence of Stroop studies that have been conducted in chronic pain patients. The keywords used in all search strategies were Stroop, chronic pain, selective attention and attentional bias. In addition, references in relevant publications were further examined and experts in the field were questioned.

Five articles and one unpublished dissertation were identified (Pearce and Morley, 1989; Boissevain, 1994; Duckworth et al., 1997; Pincus et al., 1998; Crombez et al., 2000; Snider et al., 2000). Each study had to provide sufficient information to estimate an MD (i.e. mean response latencies and standard deviations for each group for sensory pain, affective pain and control words). With regard to the study by Boissevain, only the group consisting of nondepressed pain patients and the pain- and depression-free control group were taken into account in the present meta-analysis. The study of Duckworth et al. (1997) did not provide mean response latencies. The response latencies could not be provided by the authors. In addition, in order to calculate an MD, a control group is necessary. In the study of Crombez et al. (2000) no control group was included. Both studies were therefore omitted from the analysis. The study of Pincus et al. (1998) consisted of two successive experiments which have been taken as two separate studies (referred to as ' $A$ ' and ' $B$ ') in the current review, leaving a total number of five studies for further analysis (Pearce and Morley, 1989; Boissevain, 1994; Pincus et al., 1998; Snider et al., 2000).

\section{Data collection}

In order to identify possible sources of heterogeneity, information on study characteristics was collected. Information regarding study design (publication year, study size, country), measuring instrument (computerized vs non-computerized Stroop task), source of pain patients and minimum duration of pain complaints were listed. In addition, the methodological quality of each study was systematically assessed by two authors
(J.R. and J.W.S.V.) independent of each other using a list of predefined criteria (see the Appendix). Each item was scored 1 (rating 'yes') or 0 (rating 'no' or 'don't know'). The range of the quality score was between 0 and 10 . Disagreements were solved by consulting one of the other authors (M.L.P).

\section{Statistical analysis}

A common way to examine publication bias is by visually inspecting a precision-based funnel plot asymmetry (Egger et al., 1997). In addition, the degree of asymmetry can be quantified by using Egger's unweighted regression asymmetry test (Egger et al., 1997). Because of the small number of studies in the present review, publication bias could not be examined adequately. In order to estimate a pooled MD, an individual MD was computed for each study. Therefore, for both sensory pain and affective pain words, an interference score was computed within each study, which was defined as the difference in response times (RTs) between sensory or affective words and neutral words. This was done for the chronic pain patients as well as for the healthy controls. By subtracting the interference score in the control group from the interference score in the pain group, an MD was computed for pain sensory words and pain affective words separately. The formulae are as follows:

$$
\begin{aligned}
& \text { Interference }_{(\text {sensory/affective) }}=\mathrm{RT}_{(\text {sensory/affective) }} \\
& -\mathrm{RT}_{\text {(neutral) }} \\
& \mathrm{MD}_{\text {(sensory) }}=\text { interference }_{(\text {sensory; }} \text { chronic pain group) } \\
& \text { - interference } \text { (sensory; control group) } \\
& \mathrm{MD}_{(\text {affective) }}=\text { interference }{ }_{(\text {affective; }} \text { chronic pain group) } \\
& \text { - interference }{ }_{(\text {affective; control group) }}
\end{aligned}
$$

In order to compute a $95 \%$ confidence interval (CI) for each individual MD, the standard error, reflected by the square root of the variance, is needed. The variance of the MD (VAR) is defined as the sum of the variance in each group (chronic pain group and control group) divided by its study size $(n)$. The variance in each group is equal 
to the variance of a difference score (pain words versus neutral words within each group). The formula for a difference score (dif) is defined as the sum of the variance for both the pain words and the neutral words minus twice the covariance. The formula for both sensory and affective pain words is

$$
\begin{aligned}
\operatorname{VAR}(\mathrm{MD})= & \operatorname{VAR}_{(\text {chronic pain group })} / n \\
& +\operatorname{VAR}_{(\text {control group })} / n
\end{aligned}
$$

To compute both $\mathrm{VAR}_{\text {(chronic pain group) and }}$ $\mathrm{VAR}_{\text {(control group) }}$ :

$$
\begin{aligned}
\operatorname{VAR}_{(\text {dif })}= & \mathrm{VAR}_{(\text {painwords })}+\mathrm{VAR}_{(\text {neutral words })} \\
& -2 r \times \mathrm{SD}_{(\text {pain words })} \times \mathrm{SD}_{(\text {neutral words })}
\end{aligned}
$$

In the formula, $r$ refers to the correlation between (sensory or affective) pain words and neutral words. These correlations were not provided in the individual papers but were obtained from the authors, except for the studies of Pincus et al. (1998). A pooled correlation coefficient was estimated for the Pincus et al. studies, based on the correlations from the other studies and the studies by Duckworth et al. (1997) and Crombez et al. (1999). One remark with regard to the type of Stroop study is in order. Two studies used a non-computerized Stroop task which consisted of presenting cards with sensory pain words, affective pain words and neutral words in a fixed order. The time to complete each card was measured. In order to compute an MD and a $95 \% \mathrm{CI}$, response times were transformed into mean response latencies by dividing the total response times by the amount of stimuli used within each word category.

A pooled MD and its $95 \%$ CI were estimated according to both a fixed and a random effects model using the STATA statistical software package (Stata Corporation, College Station, TX, 77845, USA, 1999). In a fixed effects model, all studies are assumed to estimate the same underlying 'fixed' effect. Differences between studies are completely due to sampling error. According to a random effects model, each study is assumed to estimate its own underlying effect, thereby allowing for variability between studies.
In the absence of (statistical) heterogeneity, both models produce asymptotically the same estimates (Zeegers et al., 2000). Furthermore, the fixed effects model unfortunately assumes that inference can be made only for the studies that are included in the meta-analysis. Only the random effects model allows for generalizability. On the other hand, a random effects model may not be appropriate because no random sampling was used to obtain the studies that could have been performed. The results from both a fixed and a random effects analysis are presented. If the MD estimations of both models do not differ substantially, the fixed effects model is interpreted. In addition, an indication of statistical heterogeneity is obtained by the $Q$ test. However, since there are only five studies in the metaanalysis, the $Q$ test has low power and should be interpreted cautiously. The between-study variance was estimated iteratively, using the empirical Bayes method. Meta-regression analysis can be used to identify possible sources of clinical and methodological heterogeneity and was used in the present study to investigate the impact of the methodological quality of the individual studies on the pooled MD (i.e. whether methodological quality is an effect modifier). If the magnitude of the pooled MD depends on the methodological quality of the studies (i.e. methodological quality is a significant effect modifier), then the pooled MD should be estimated separately according to each category of the effect modifier.

\section{RESULTS}

\section{Study characteristics}

Table 1 displays study characteristics which may account for heterogeneity between studies.

\section{MD estimation}

Table 2 shows the MD estimations and their 95\% CIs for both sensory and affective pain words for each study. In addition, the pooled MD and its $95 \%$ CI for both a fixed and a random effects model are presented. Figure 1 summarizes 
TABLE 1. Study characteristics of five studies concerning attentional bias in chronic pain patients using the modified Stroop task, ordered by year of publication.

\begin{tabular}{|c|c|c|c|c|c|}
\hline Reference & Country & $\begin{array}{l}\text { Measuring } \\
\text { instrument }\end{array}$ & $\begin{array}{l}\text { Source of } \\
\text { pain patients }\end{array}$ & $N_{\mathrm{e}} / N_{\mathrm{c}}^{\mathrm{a}}$ & $\begin{array}{l}\text { Duration of } \\
\text { pain complaints }\end{array}$ \\
\hline Pearce and Morley (1989) & UK & Non-computerized & $\begin{array}{l}\text { Chronic pain patients } \\
\text { (not specified) }\end{array}$ & $16 / 16$ & 1 year \\
\hline Boissevain (1994) & Canada & Non-computerized & $\begin{array}{l}\text { Various types of } \\
\text { pain patients }\end{array}$ & $15 / 15$ & 6 months \\
\hline Pincus et al. (1998), study A & UK & Non-computerized & $\begin{array}{l}\text { Chronic pain patients } \\
\text { (not specified) }\end{array}$ & $20 / 20$ & 6 months \\
\hline Pincus et al. (1998), study B & UK & Computerized & $\begin{array}{l}\text { Chronic pain patients } \\
\text { (not specified) }\end{array}$ & $17 / 17$ & 6 months \\
\hline Snider et al. (2000) & Canada & Computerized & $\begin{array}{l}\text { Chronic back and/or } \\
\text { neck pain }\end{array}$ & $33 / 33$ & 3 months \\
\hline
\end{tabular}

${ }^{\mathrm{a}} N_{\mathrm{e}}$, number of patients; $N_{\mathrm{c}}$, number of healthy controls.

TABLE 2. MD estimations and their $95 \%$ Cls.

\begin{tabular}{lccrr}
\hline Reference & $\mathrm{MD}_{\text {(sensory) }}$ & $95 \% \mathrm{Cl}_{\text {(sensory) }}$ & $\mathrm{MD}_{\text {(affective) }}$ & $95 \% \mathrm{Cl}_{\text {(affective) }}$ \\
\hline Pearce and Morley (1989) & 102.4 & $26.0,178.0$ & 108.6 & $12.8,195.4$ \\
Boissevain (1994) & 42.0 & $-3.0,96.0$ & 36.0 & $-0.8,72.8$ \\
Pincus et al. (1998), study A & 41.6 & $-9.8,93.0$ & -30.6 & $-84.7,23.5$ \\
Pincus et al. (1998), study B & 4.0 & $-46.9,54.9$ & 32.0 & $-19.4,83.4$ \\
Snider et al. (2000) & 18.0 & $-3.4,39.4$ & 29.0 & $3.8,46.3$ \\
Pooled (fixed) & 26.5 & $10.0,42.9$ & 28.0 & $11.9,44.2$ \\
Pooled (random) & 31.5 & $7.6,55.4$ & 28.1 & $0.4,55.8$ \\
\hline
\end{tabular}
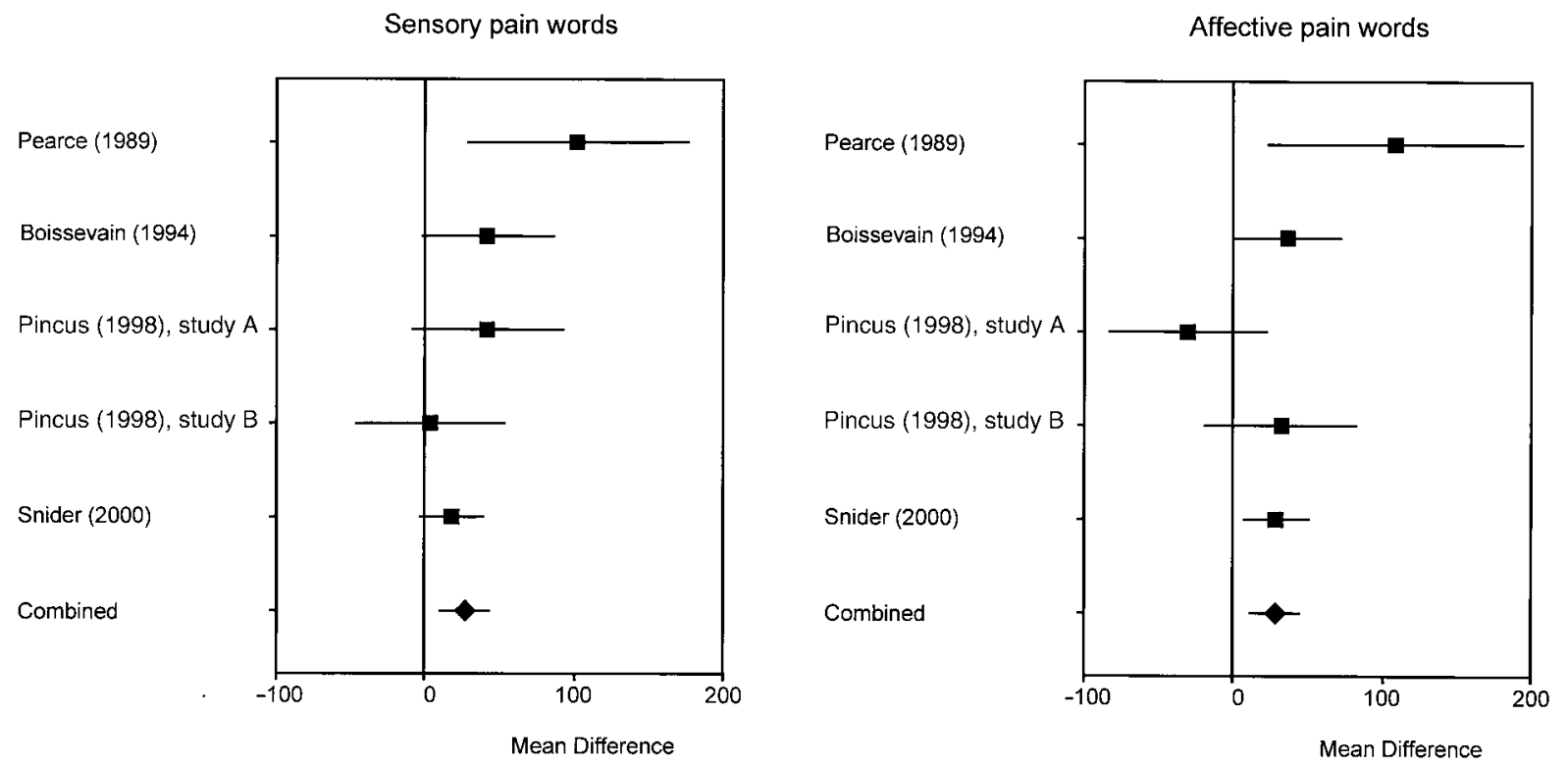

FIG. 1. Forest plots for sensory and affective pain words displaying MDs and their $95 \%$ Cls for individual studies and the pooled estimation. 
TABLE 3. Ratings of methodological quality of each study.

\begin{tabular}{lccccc}
\hline & $\begin{array}{c}\text { Pearce and } \\
\text { Morley (1989) }\end{array}$ & $\begin{array}{c}\text { Boissevain } \\
(1994)\end{array}$ & $\begin{array}{c}\text { Pincus et al. } \\
\text { (1998), study A }\end{array}$ & $\begin{array}{c}\text { Pincus et al. } \\
\text { (1998), study B }\end{array}$ & $\begin{array}{c}\text { Snider } \\
\text { el. (2000) }\end{array}$ \\
\hline 1. Inclusion criteria & 1 & 1 & 1 & 1 & 1 \\
2. Exclusion criteria & 0 & 1 & 0 & 0 & 1 \\
3. Type of patients & 0 & 1 & 0 & 0 & 1 \\
4. Matching patients & 1 & 1 & 1 & 0 & 0 \\
5. Environment & 0 & 0 & 0 & 1 & 1 \\
6. Computerized Stroop & 0 & 0 & 0 & 1 & 1 \\
7. Matching words & 1 & 1 & 1 & 1 & 1 \\
8. Depression & 0 & 1 & 1 & 1 & 1 \\
9. Anxiety & 0 & 0 & 1 & 7 & 9 \\
10. Statistical analysis & 1 & 1 & 6 & & 1 \\
Total quality score & 4 & 7 & & & 1 \\
\hline
\end{tabular}

the MDs and their 95\% CIs for each study and the pooled MD estimation in a graphical way.

As both the fixed effects model and the random effects model yield comparable MD estimation for sensory pain words as well as for affective pain words, the fixed effects model is interpreted for both word categories. In addition, the $Q$ value was $6.20(p=0.185)$ for sensory pain words and $8.31(p=0.079)$ for affective pain words, tentatively indicating the absence of statistical heterogeneity. According to Table 2, for sensory pain words an MD of 26.5 was found $(95 \%$ CI $10.0-42.9 ; p=0.002)$ and for affective pain words an MD of 28.0 was found $(95 \%$ CI $11.9-44.2 ; \quad p=0.001)$. With regard to the methodological quality of each study, Table 3 shows the ratings for each study. Inter-rater agreement measured by $\kappa$ was 0.91 , indicating very good strength of agreement (Altman, 1997). Meta-regression analysis indicated that the methodological quality of the various studies did not significantly affect the pooled MD estimation for both sensory pain words $(p=0.058)$ and affective pain words $(p=0.557)$.

\section{DISCUSSION}

The purpose of the present study was to review by means of a meta-analysis whether chronic pain patients display attentional bias towards painrelated information on a modified Stroop task. The results can be summarized as follows: (a) significant MD estimations (in milliseconds) were found for both sensory pain words $(\mathrm{MD}=26.7 ; 95 \%$ CI $10.0-42.9)$ and affective pain words $(\mathrm{MD}=28.1 ; 95 \%$ CI $0.4-55.8)$ (b) a meta-regression analysis to examine whether the methodological quality of the various studies influenced the MDs did not reach statistical significance for both sensory pain words and affective pain words. Thus, although the various studies differed with regard to the methodological quality, the MD estimations for both sensory pain words and affective pain words tentatively indicated a rather consistent pattern. The MD estimations provided in Table 2 allow researchers to compute power and sample sizes. One may choose either the combined MD or, in a more conservative way, the MD provided by Pincus et al. (1998), study B.

Recently, Pincus and Morley (2001) proposed a so-called 'enmeshment model' to account for evidence regarding attention, interpretation and recall biases in chronic pain patients. According to this model, biases in information processing in chronic pain are the result of overlap between three schemata: pain, illness and self. With frequent repeated or continued experience of pain, the pain schema becomes enmeshed with illness and self schemata. The extent of the enmeshment and the salient content of the schema determine the bias. A fundamental assumption is that all pain patients selectively process sensory intensity information. The results from the present metaanalysis are consistent with this assumption. The pooled data suggest that chronic pain patients selectively attend to sensory stimuli. Moreover, 
chronic pain patients also selectively attend to affective pain words.

Lately, research into information processing bias in chronic pain patients has shifted from investigating the role of pain itself to the role of depression and anxiety (pain-related fear in particular). The influence of mood state (i.e. depression and anxiety) on the observed MD cannot be investigated in the present metaanalysis but should be examined within each study instead. Some studies have indeed found some support for the idea that an attentional bias can also be accounted for as arising from mood state (Pincus et al., 1998; Snider et al., 2000), whereas other have not (Pearce and Morley, 1989; Boissevain, 1994). Depression has been found to be associated with a general delay in colour naming latencies on a Stroop. The role of anxiety (or pain-related fear), however, is less clear. However, according to the cognitive theory of anxiety, the most important function of anxiety is facilitating the early detection of potentially dangerous stimuli (Eysenck, 1992). Therefore, anxiety represents a shift into a mode of hypervigilance, such that the person scans the environment for any threatening stimulus, particularly those that have been associated with threat-related stimuli. This is also called 'specific hypervigilance'. Highly anxious individuals also tend to pay attention to any irrelevant (neutral) stimuli. This is called 'general hypervigilance'. In the case of chronic pain, one may wonder whether chronic pain patients with pain-related fear display an attentional bias (i.e. are hypervigilant) to pain-related information. According to the fear-avoidance model as proposed by Vlaeyen et al. (1995) and Vlaeyen and Linton (2000), pain-related fear may induce a state of hypervigilance (i.e. increased attention for pain and other somatosensory signals). Thus, it may be proposed that only a subgroup of chronic pain patients, namely those with painrelated fear, display an attentional bias. Some evidence for this has been found in a study of Peters and colleagues, in which pain-related fear appeared to be associated with superior detection of weak electrical stimuli (Peters et al., 2000), and in a study of Crombez et al (1999), in which attentional interference (measured by a numerical interference test) in 40 chronic pain patients was found to be best predicted by the interaction between pain severity and painrelated fear.

Some limitations of the present meta-analysis need further addressing. First, only five articles could be identified. Although considerable effort has been put into identifying all suitable studies for the present meta-analysis, the presence of unpublished studies cannot be completely ruled out. If the results from these unpublished studies do not support the idea that chronic pain patients may exhibit an attentional bias towards pain related information, the pooled estimation in the present study might be an overestimation of the 'true estimation'. Second, the assessment of the methodological quality could not be blinded as both raters were familiar with the individual articles. Although most criteria were to be rated in an objective manner, some degree of subjectivity might have been associated with the assessment of the methodological quality. Third, although significant MD estimations were found for both sensory pain words and affective pain words, it should be born in mind that the fixed effects model does not allow extrapolation of the results obtained in the present meta-analysis. A random effects model, which yielded comparable results, allows for generalization.

Some doubts have been expressed whether the modified Stroop paradigm is a pure measure of attentional bias or some other information processing (e.g. preoccupation with word meaning) or motor response (e.g. production of appropriate verbal response). The modified Stroop paradigm might therefore be a measure of more general information processing bias instead of pure attentional bias.

The dot-probe paradigm, another widely used technique to investigate attentional bias, may overcome these limitations. The dot-probe is assumed to represent a more direct test of allocation of visual attention thereby eliminating interpretations of results that are associated with stages of information processing unrelated to attention and to the production of a response. Using a dot-probe procedure with a mixture of sensory pain and affective pain words selected from the McGill Pain Questionnaire, 
Asmundson et al. (1997) found no evidence for an attentional bias in chronic pain patients. However, when the patients were divided on the basis of their scores on a measure of anxiety sensitivity (i.e. the proneness to experience fear in response to anxiety-related sensations), those with low anxiety sensitivity shifted attention away from pain-related stimuli whereas those with high anxiety sensitivity attended equally to pain and neutral stimuli. The observation that low anxietyprone individuals become more avoidant of threat is in line with the interaction hypothesis concerning attentional biases, which suggests that, when state anxiety or stress increases, high trait anxiousindividuals become more vigilant, whereas low trait anxious individuals become more avoidant of threat (Mogg and Bradley, 1998).

Keogh et al. (2000) investigated in healthy volunteers whether individuals high in fear of pain would selectively attend towards painrelated information using a dot-probe paradigm. Participants were allocated to three groups based on their scores on the Fear of Pain Questionnaire (McNeil and Rainwater, 1998). Furthermore, selectivity of the attentional bias was investigated by including social threat words and positive words. The results from this study suggested that those with high fear of pain exhibited a selective attentional bias towards pain-related information, compared with those classified as low in fear of pain. No attentional effects were found for social threat words or for positive words. Similar results were found in a subsequent dot-probe study in which individuals were selected on the basis of physical anxiety sensitivity (Keogh et al., 2001). Those high in physical anxiety were found to exhibit a selective attentional bias for physically threatening material. However, other studies applying a dot-probe paradigm have failed to find evidence for attentional bias in individuals high on pain-related fear (Keogh and Cochrane, submitted; Roelofs et al., in preparation).

In conclusion, this study reviewed by means of a meta-analysis whether chronic pain patients selectively attend to pain-related information using a modified Stroop paradigm. The metaanalysis indicated that chronic pain patients selectively attend to sensory pain words and affective pain words as measured by a modified
Stroop paradigm. However, in the light of the limitations, in particular the small number of studies included in the present meta-analysis, one can only impute moderate confidence to the MD estimations. The conclusion from the metaregression analyses, showing that methodological quality does not influence the MD estimations, can only be drawn tentatively. Taken together, employing a modified Stroop paradigm has yielded evidence for attentional bias towards pain-related words. However, future research should open up the way to other paradigms (i.e. dot-probe) which may offer a more rigorous test of attentional bias, thereby possibly yielding more robust effects.

\section{ACKNOWLEDGEMENTS}

The authors would like to express their greatest gratitude to Gordon Asmundson, Michael Boissevain, Geert Crombez, Danielle Hale, Stephen Morley and Tamar Pincus for their assistance in preparing this manuscript.

\section{REFERENCES}

Altman DG. Practical Statistics for Medical Research. London: Chapman \& Hall, 1997.

Asmundson G, Kuperos J, Norton G. Do patients with chronic pain selectively attend to pain-related information? Preliminary evidence for the medicating role of fear. Pain 1997; 72: 27-32.

Beck AT. Cognitive Therapy and the Emotional Disorders. New York: International Universities Press, 1976.

Beck AT, Emerey G, Greenberg RC. Anxiety Disorders and Phobias: a Cognitive Perspective. New York: Basic Books, 1986.

Boissevain MD. Information processing in chronic pain: the role of depression. Unpublished thesis. University of Western Ontario, Canada, 1994.

Bower GH. Mood and memory. Am Psychol 1981; 36: 129-148.

Bower GH. Commentary on mood and memory. Behav Res Ther 1987; 25: 443-456.

Crombez G, Eccleston C, Baeyens F, Van Houdenhove B, Van de Broeck A. Attention to chronic pain is dependent upon pain-related fear. J Psychosom Res 1999; 47(5): 403-410.

Crombez G, Hermans D, Adriaensen H. The emotional stroop task and chronic pain: what is threatening for chronic pain sufferers? Eur J Pain 2000; 4(1): 37-44. 
Duckworth MP, Iezzi A, Adams HE, Hale D. Information processing in chronic pain disorder: a preliminary analysis. J Psychopathol Behav Assess 1997; 19(3): 239-255.

Egger M, Davey Smith G, Schneider M, Minder C. Bias in meta-analysis detected by a simple, graphical test. $\mathrm{Br}$ Med J 1997; 315: 629-634.

Eysenck MW. Anxiety: the Cognitive Perspective. Hove: Earlbaum, 1992.

Keogh E, Ellery D, Hunt C, Hannent I. Selective attentional bias for pain-related stimuli amongst pain fearful individuals. Pain 2000; 91: 91-100.

Keogh E, Dillon C, Georgiou G, Hunt C. Selective attentional biases for physical-threat in physical anxiety sensitivity. J Anxiety Dis 2001; 15: 299-315.

McCracken LM, Zayfert C, Gross RT. The Pain Anxiety Symptoms Scale: development and validation of a scale to measure fear of pain. Pain 1992; 50(1): 67-73.

McNeil DW, Rainwater AJ. Development of the Fear of Pain Questionnaire-III. J Behav Med 1998; 21: 389-410.

Mogg K, Bradley BP. A cognitive-motivational analysis of anxiety. Behav Res Ther 1998; 36: 809-848.

Pearce J, Morley S. An experimental investigation of the construct validity of the McGill Questionnaire. Pain 1989; 39: $115-121$.

Peters M, Vlaeyen JWS, Van Drunen C. Do fibromyalgia patients display hypervigilance for innocuous somatosensory stimuli? Application of a body scanning reaction time paradigm. Pain 2000; 86: 283-292.

Pincus T. Assessing psychological factors in chronic pain-a new approach. Phys Ther Rev 1998; 3: 41-45.
Pincus T, Morley S. Cognitive processing in chronic pain: a review and integration. Psychol Bull 2001; 127: 599-617.

Pincus T, Pearce S, McClelland A, Turner-Stokes L. Selfreferential selective memory in pain patients. $\mathrm{Br} \mathrm{J}$ Clin Psychol 1993; 32: 365-374.

Pincus T, Pearce S, McClelland A, Farley S, Vogel S. Interpretation bias in responses to ambiguous cues in pain patients. J Psychosom Res 1994, 38(4): 347-353.

Pincus T, Pearce S, Perrott A. Paint patients' bias in the interpretation of ambiguous homophones. $\mathrm{Br} \mathrm{J} \mathrm{Med}$ Psychol 1996; 69(3): 259-266.

Pincus T, Fraser L, Pearce S. Do chronic pain patients 'stroop' on pain stimuli? Br J Clin Psychol 1998; 37: 49-58.

Reiss S, Peterson RA, Gursky DM, McNally RJ. Anxiety sensitivity, anxiety frequency and the prediction of fearfulness. Behav Res Ther 1986; 24: 1-8.

Snider BS, Asmundson GJ, Wiese KC. Automatic and strategic processing of threat cues in patients with chronic pain: a modified stroop evaluation. Clin J Pain 2000; 16(2): 144-154.

Vlaeyen JWS, Linton SJ. Fear-avoidance and its consequences in chronic musculoskeletal pain: a state of the art. Pain 2000; 85: 317-332.

Vlaeyen JWS, Kole-Snijders A, Boeren R, Van Eek H. Fear of movement/re(injury) in chronic low back pain and its relation to behavioral performance. Pain, 1995; 62: 363-372.

Zeegers MP, Heisterkamp SH, Kostense PJ, Van der Windt DA, Scholten RJ. The practice of systematic reviews. VII. Pooling the results of observational studies. Ned Tijdschr Geneeskd 2000; 144: 1393-1397.

\section{APPENDIX: CRITERIA LIST FOR THE ASSESSMENT OF THE METHODOLOGICAL QUALITY}

1. Were the inclusion criteria specified?

2. Were the exclusion criteria specified?

3. Were the type of pain patients described?

4. Were controls matched?

5. Did controls share the same (medical) environment?

6. Was a computerized version of the Stroop task administered?

7. Were words matched?

8. Were levels of depression adequately assessed?

9. Were levels of anxiety (or pain-related fear) adequately assessed?

10. Was the statistical analysis appropriate?

\begin{abstract}
Yes/no/don't know
Yes/no/don't know

Yes/no/don't know

Yes/no/don't know

Yes/no/don't know

Yes/no/don't know

Yes/no/don't know

Yes/no/don't know

Yes/no/don't know

Yes/no/don't know
\end{abstract}

'Yes' is rated as 1 point whereas 'no' and 'don't know' are rated as 0 points. 